\title{
Efficacy and safety of deflazacort vs prednisone and placebo for Duchenne muscular dystrophy
}

\section{OPEN}

Robert C. Griggs, MD J. Phillip Miller Cheryl R. Greenberg, MD Darcy L. Fehlings, MD Alan Pestronk, MD Jerry R. Mendell, MD Richard T. Moxley III, MD

Wendy King, PT John T. Kissel, MD Valerie Cwik, MD Michel Vanasse Julaine M. Florence, DPT Shree Pandya, DPT Jordan S. Dubow, MD James M. Meyer, PharmD

Correspondence to Dr. Griggs:

Robert_Griggs@URMC. Rochester.edu

\section{Supplemental data} at Neurology.org

\section{ABSTRACT}

Objective: To assess safety and efficacy of deflazacort (DFZ) and prednisone (PRED) vs placebo in Duchenne muscular dystrophy (DMD).

Methods: This phase III, double-blind, randomized, placebo-controlled, multicenter study evaluated muscle strength among 196 boys aged 5-15 years with DMD during a 52-week period. In phase 1, participants were randomly assigned to receive treatment with DFZ $0.9 \mathrm{mg} / \mathrm{kg} / \mathrm{d}$, DFZ $1.2 \mathrm{mg} / \mathrm{kg} / \mathrm{d}$, PRED $0.75 \mathrm{mg} / \mathrm{kg} / \mathrm{d}$, or placebo for 12 weeks. In phase 2, placebo participants were randomly assigned to 1 of the 3 active treatment groups. Participants originally assigned to an active treatment continued that treatment for an additional 40 weeks. The primary efficacy endpoint was average change in muscle strength from baseline to week 12 compared with placebo. The study was completed in 1995.

Results: All treatment groups (DFZ $0.9 \mathrm{mg} / \mathrm{kg} / \mathrm{d}$, DFZ $1.2 \mathrm{mg} / \mathrm{kg} / \mathrm{d}$, and PRED $0.75 \mathrm{mg} / \mathrm{kg} / \mathrm{d}$ ) demonstrated significant improvement in muscle strength compared with placebo at 12 weeks. Participants taking PRED had significantly more weight gain than placebo or both doses of DFZ at 12 weeks; at 52 weeks, participants taking PRED had significantly more weight gain than both DFZ doses. The most frequent adverse events in all 3 active treatment arms were Cushingoid appearance, erythema, hirsutism, increased weight, headache, and nasopharyngitis.

Conclusions: After 12 weeks of treatment, PRED and both doses of DFZ improved muscle strength compared with placebo. Deflazacort was associated with less weight gain than PRED.

Classification of evidence: This study provides Class I evidence that for boys with DMD, daily use of either DFZ and PRED is effective in preserving muscle strength over a 12-week period. Neurology ${ }^{\circledast}$ 2016;87:2123-2131

\section{GLOSSARY}

$\mathbf{A E}=$ adverse event; $\mathbf{B M D}=$ Becker muscular dystrophy; $\mathbf{B M I}=$ body mass index; $\mathbf{C l}=$ confidence interval; $\mathbf{D F Z}=$ deflazacort; DMD = Duchenne muscular dystrophy; FVC = forced vital capacity; GC = glucocorticoid; ITT = intent-to-treat; LS = least squares; MRC = Medical Research Council; PRED = prednisone; SAE = serious adverse event.

Duchenne muscular dystrophy (DMD) is an X-linked disease that affects approximately 1 in 5,000 live male births. ${ }^{1}$ The disease presents in boys typically before the age of 5 years. ${ }^{2}$ Without treatment, boys require a wheelchair before their teen years due to deterioration of muscle strength. ${ }^{3}$ Currently, glucocorticoids (GCs) are the only pharmacologic therapy shown to increase muscle strength among boys with DMD., ${ }^{2,3}$ Corticosteroids prolong independent ambulation, improve pulmonary function, delay the onset of cardiomyopathy, and reduce the incidence of scoliosis. ${ }^{2-4}$ While numerous, well-controlled studies had been conducted on prednisone (PRED) in the DMD population at the time this study was conducted, no such evidence existed for deflazacort (DFZ). ${ }^{5-7}$

\footnotetext{
From the University of Rochester Medical Center (R.C.G., R.T.M., S.P.), NY; Washington University in St Louis (J.P.M., A.P., J.M.F.), MO; University of Manitoba and Children's Hospital Research Institute of Manitoba (C.R.G.), Winnipeg; Department of Paediatrics (D.L.F.), Holland Bloorview Kids Rehabilitation Hospital, University of Toronto, Canada; Nationwide Children's Hospital (J.R.M.); Ohio State University Wexner Medical Center (W.K., J.T.K.), Columbus; Muscular Dystrophy Association (V.C.), Marlton, NJ; CHU Sainte Justine (M.V.), Montreal, Canada; and Marathon Pharmaceuticals, LLC (J.S.D., J.M.M.), Northbrook, IL.

Go to Neurology.org for full disclosures. Funding information and disclosures deemed relevant by the authors, if any, are provided at the end of the article. The Article Processing Charge was paid by Marathon Pharmaceuticals, LLC.

This is an open access article distributed under the terms of the Creative Commons Attribution-NonCommercial-NoDerivatives License 4.0 (CC BY-NC-ND), which permits downloading and sharing the work provided it is properly cited. The work cannot be changed in any way or used commercially.
} 
DFZ is a heterocyclic GC prodrug belonging to the class of oxazoline steroids, with demonstrated anti-inflammatory and immunosuppressant effects. ${ }^{8}$ Previous studies have suggested that DFZ and PRED are effective and suggest that DFZ may cause less weight gain than PRED. ${ }^{9,10}$ This study examined the efficacy of DFZ vs placebo and compares the efficacy and safety of DFZ with PRED. An abstract of this study was presented. ${ }^{11}$ Although the study was completed in 1995, the data are being published now due to the efforts of the authors and Marathon Pharmaceuticals since the original sponsor of the study gave up the rights to the data and compound. Marathon has submitted a New Drug Application in 2016 for US approval of deflazacort for the treatment of DMD.

METHODS Study design. In a multicenter, phase 3, randomized, double-blind, placebo-controlled trial, 196 boys (age 5-15 years) with DMD were assigned to groups with a permuted block system via telephone, and both study personnel and participants were masked to treatment assignment. The study consisted of 2 phases. In phase 1, eligible participants were randomly assigned to 1 of 4 groups stratified by center and by whether the participant was classified as ambulatory or nonambulatory and randomized in blocks of 4: DFZ $0.9 \mathrm{mg} / \mathrm{kg} / \mathrm{d}$, DFZ $1.2 \mathrm{mg} / \mathrm{kg} / \mathrm{d}$, PRED $0.75 \mathrm{mg} / \mathrm{kg} / \mathrm{d}$, or placebo for 12 weeks of treatment. If 2 brothers participated in the study, they were randomized together in the same treatment group to prevent any confusion in taking their medication. After the initial 12 weeks, in phase 2 , placebo-treated participants were randomly re-assigned to 1 of the 3 active treatment groups and followed through 52 weeks. Participants originally assigned to 1 of the 3 active treatment groups continued in that study arm for the additional 40 weeks. All participants in each of the treatment groups received the same number of tablets to maintain blinding. The study was conducted between April 26, 1993 and April 20, 1995

Participant selection. Eligible participants were boys between the ages of 5 and 15 years, with onset of weakness before 5 years of age; increased serum creatine kinase activity at least 10 times the upper limit of normal; and either genetic analysis of the dystrophin gene or biopsy that demonstrated a clear alteration in dystrophin amount or distribution in the muscle. The protocol enrolled participants with Becker muscular dystrophy (BMD) or DMD, describing differences in dystrophin analysis findings from muscle biopsy specimens. Differentiation between DMD and $\mathrm{BMD}$ was less definitive at the time of this study than it is today. Clinical diagnostic criteria were used by the Clinical Investigation in Duchenne Dystrophy study group to distinguish patients with DMD from those with BMD, since DNA analysis was not always definitive. Emphasis was placed on examination for clinical differentiation in addition to muscle biopsies. Patients with BMD characteristically have good neck flexor strength, clearly in the 4 range, and usually against resistance, whereas patients with DMD have weaker neck flexors even from early in the course of their disease. A total of 7/196 ( 3.6\%) participants presented with neck flexor grades of 4 or greater at the screening visit.

Exclusion criteria included prior long-term use ( $>1$ year) of oral GCs, active peptic ulcer disease or history of gastrointestinal bleeding or perforation, any use of oral steroids for $\geq 1$ month within 6 months of study entry, any use of oral steroids for $<1$ month within 2 months of study entry, normal muscle biopsy or muscle biopsy evidence of denervation, glycogen storage disease, or skin rash suggestive of dermatomyositis.

Standard protocol approvals, registrations, and patient consents. This trial was designed and monitored in accordance with the ethical principles of good clinical practice as required by the major regulatory authorities, and in accordance with the Declaration of Helsinki. Written informed consent was received prior to study enrollment from at least 1 parent or legal guardian, as appropriate, and from participants if aged 14 years or older. The protocol (and any amendments) and the statement of informed consent were approved by an institutional review board prior to each center's initiation.

Procedures. Efficacy assessments. The primary efficacy assessment was the change from baseline to week 12 in average muscle strength as assessed by modified Medical Research Council (MRC) scale, used in previous studies with PRED. ${ }^{5-7}$ The study was completed in 1995, at which time the 6-minute walk distance test was not used as an endpoint. The MRC scale was considered the most relevant efficacy measure based on previous studies during this time. Participants were asked to perform specific muscle strength assessments by a trained physiotherapist in various positions (sitting, prone, side-lying, and supine) at each study visit to evaluate any change in disease severity during the study and graded with an 11-point scale.

Secondary efficacy endpoints included change in average muscle strength from week 12 to week 52 and pulmonary function testing (i.e., forced vital capacity $[\mathrm{FVC}]$ and maximum voluntary ventilation). Additional endpoints included timed functional testing: standing from lying position; climbing 4 stairs; running/walking 30 feet; and propelling a wheelchair 30 feet. In addition, physicians made a global assessment of each participant's disease severity at each visit using the Response Visual Analog Scale $(0 \mathrm{~mm}=$ no symptoms; $100 \mathrm{~mm}=$ as bad as it could be). ${ }^{10}$

Safety assessments. Safety was evaluated by the incidence of adverse events (AEs), changes in clinical laboratory findings or physical examinations, and vital signs (including weight, height, and body mass index [BMI]). In addition, change in statural growth percentiles was evaluated.

Statistical analyses. The sample size calculations for this study were based on a previous double-blind, placebo-controlled trial of PRED in 99 participants that showed a difference of 0.34 units in average manual muscle strength score after 3 months. ${ }^{5}$ The SD of the difference measure was 0.33 units. When translated into the present study, these findings had adequate power $(90 \%)$ with 36 participants in each of the 4 groups to detect a difference of 0.25 units ( 2 sample $t$ test). However, this sample size did not take into account any adjustment of the significance level. A sample size of 45 participants per group was sufficient to apply the Dunnett test. This sample size likewise enabled detection of a difference of $1.00-1.25 \mathrm{mo} / \mathrm{y}$ with respect to bone age delay and statural age delay.

Two analysis populations were planned for this study. The safety population included all participants who received at least 1 dose of study medication. The intent-to-treat (ITT) population included all participants randomized into the study. The efficacy 
analyses were conducted using the ITT population. All safety analyses were conducted using the safety population, except for the analysis on statural growth, in which the ITT population was analyzed. Least squares (LS) means or odds ratios and 95\% confidence intervals (CIs) are presented for statistical models, as appropriate. Statistical testing was performed at the 0.05 level using 2-tailed tests. For efficacy analyses, the baseline value was defined as the mean of the assessments obtained from visits 1 and 2 when data from both were present. If data from only 1 visit were present, the values from that visit were used as the baseline value.

Classification of evidence. This interventional study provides Class I evidence that DFZ is equivalent to PRED and provides a significant improvement compared with placebo (DFZ 0.9 $\mathrm{mg} / \mathrm{kg} / \mathrm{d}$ LS mean 0.25 vs placebo LS mean $-0.1, p=0.017$, 95\% CI 0.04-0.46; DFZ $1.2 \mathrm{mg} / \mathrm{kg} / \mathrm{d}$ LS mean 0.36 vs placebo LS mean $-0.1, p=0.0003$, 95\% CI 0.14-0.57) in average muscle strength after 12 weeks of treatment in boys with DMD.

RESULTS Participants. A total of 196 participants (figure 1) from 4 centers in the United States and 5 centers in Canada were enrolled in the study (table 1). Most of the participants were white (185 [94.9\%]) and all 196 participants were male. Overall mean (SD) participant age was 8.8 (2.89) years; weight,
30.5 (13.8) kg; height, 131 (18) cm; and BMI, $17.1(3.7) \mathrm{kg} / \mathrm{m}^{2}$. These characteristics were similar among all treatment groups.

Efficacy evaluations. The primary efficacy analysis demonstrated a significant LS mean difference in favor of DFZ $0.9 \mathrm{mg} / \mathrm{kg} / \mathrm{d}(0.25$ vs $-0.1, p=$ 0.017, 95\% CI 0.04-0.46), DFZ $1.2 \mathrm{mg} / \mathrm{kg} / \mathrm{d}$ (0.36 vs $-0.1, p=0.0003$, 95\% CI 0.14-0.57), and PRED $0.75 \mathrm{mg} / \mathrm{kg} / \mathrm{d}(0.37$ vs $-0.1, p=$ 0.0002 , 95\% CI 0.15-0.59) compared with placebo in muscle strength at 12 weeks (figure 2A). Significant improvements in motor function with the active treatments occurred with DFZ $0.9 \mathrm{mg} / \mathrm{kg} / \mathrm{d}$ ( $p=$ $0.0018)$, DFZ $1.2 \mathrm{mg} / \mathrm{kg} / \mathrm{d}(p=0.0002)$, and PRED $(p=0.0016)$ in time from supine to standing vs placebo; time to climb 4 stairs $(p<0.0001$ for all active treatments vs placebo); and time to run or walk 30 feet $(p<0.0001$ for all active treatments vs placebo) at week 12 . The absolute time to propel a wheelchair 30 feet was faster in the 3 treatment groups compared with placebo; however, these results were not significant.

Figure 1 Study schematic and patient disposition

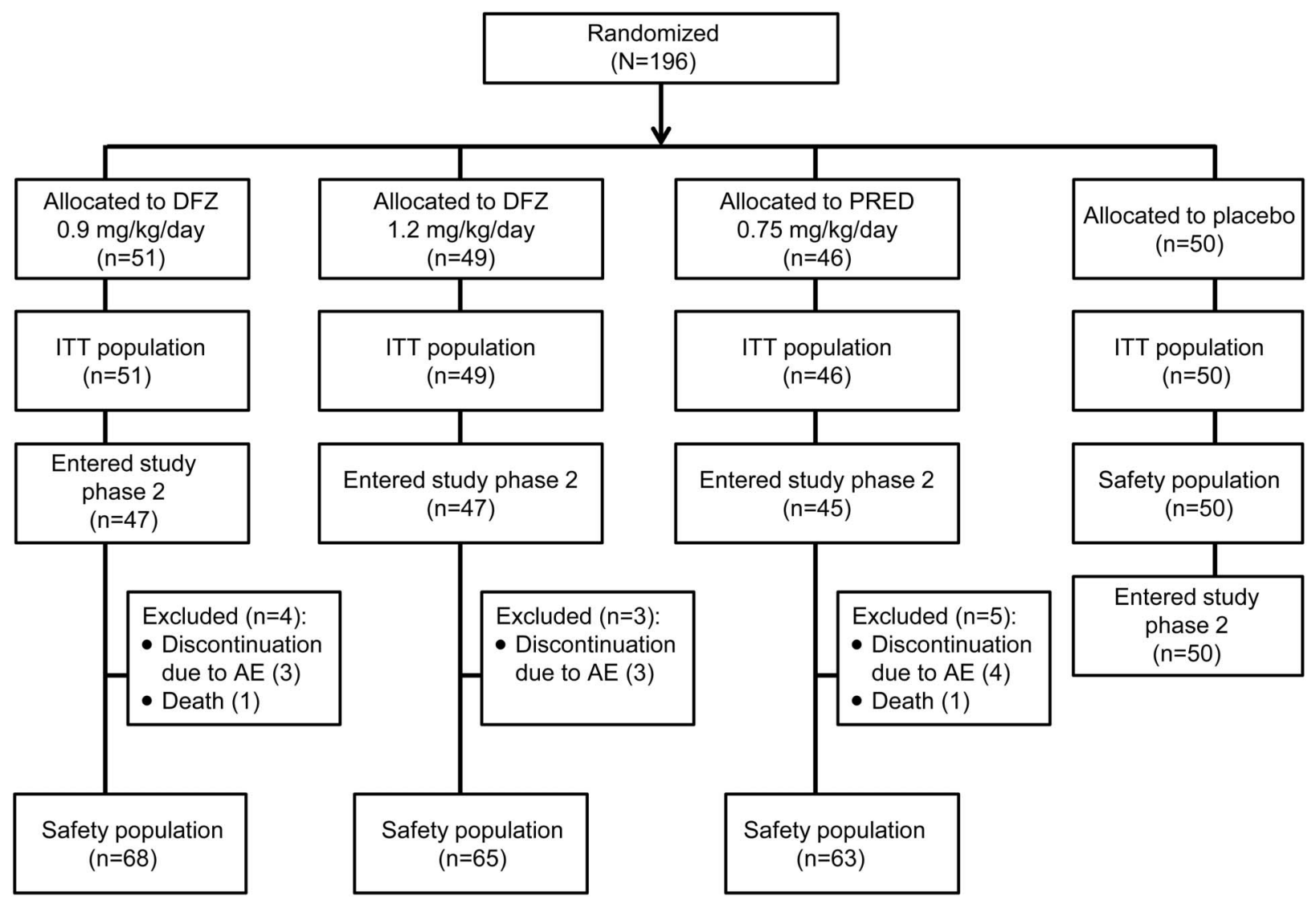

Participants enrolled were initially allocated to 1 of the 4 treatment groups (study phase 1). Participants were treated for 12 weeks. After 12 weeks, placebo participants were randomly allocated to 1 of the 3 active treatment groups and all participants were treated until week 52 . The intention-to-treat (ITT) population included all participants who were randomized and had at least 1 postbaseline assessment. The safety population included all participants who received at least 1 dose of study medication. $A E=$ adverse event; DFZ = deflazacort; PRED = prednisone. 
Table 1 Demographic and baseline characteristics

\begin{tabular}{|c|c|c|c|c|c|}
\hline \multirow[b]{2}{*}{ Variable } & \multicolumn{2}{|l|}{ Deflazacort } & \multirow[b]{2}{*}{$\begin{array}{l}\text { Prednisone } 0.75 \\
\mathrm{mg} / \mathrm{kg} / \mathrm{d}(\mathrm{n}=46)\end{array}$} & \multirow[b]{2}{*}{$\begin{array}{l}\text { Placebo } \\
(n=50)\end{array}$} & \multirow[b]{2}{*}{$\begin{array}{l}\text { Total } \\
(n=196)\end{array}$} \\
\hline & $\begin{array}{l}0.9 \mathrm{mg} / \mathrm{kg} / \mathrm{d} \\
(\mathrm{n}=51)\end{array}$ & $\begin{array}{l}1.2 \mathrm{mg} / \mathrm{kg} / \mathrm{d} \\
(\mathrm{n}=49)\end{array}$ & & & \\
\hline \multicolumn{6}{|l|}{ Age, y } \\
\hline Mean (SD) & $8.8(2.5)$ & 8.8 (3.0) & $8.8(2.9)$ & 8.5 (3.1) & $8.8(2.9)$ \\
\hline Median & 9 & 8 & 8 & 7 & 8 \\
\hline Min, $\max$ & 5,15 & 5,15 & 5,15 & 5,15 & 5,15 \\
\hline Male, n (\%) & 51 (100) & 49 (100) & $46(100)$ & 50 (100) & $196(100)$ \\
\hline \multicolumn{6}{|l|}{ Race, n (\%) } \\
\hline White & $46(90.2)$ & 45 (91.8) & 45 (97.8) & 49 (98) & $185(94.4)$ \\
\hline Asian & $0(0)$ & $1(2)$ & $0(0)$ & $0(0)$ & $1(0.5)$ \\
\hline Other & $5(9.8)$ & $3(6.1)$ & 1 (2.2) & 1 (2.0) & $10(5.1)$ \\
\hline \multicolumn{6}{|l|}{ Height, cm } \\
\hline Mean (SD) & $131(17)$ & $130(20)$ & 131 (18) & $130(18)$ & 131 (18) \\
\hline Median & 128.5 & 127 & 127.9 & 123.1 & 127.7 \\
\hline Min, max & $101.6,180.0$ & $97.0,169.6$ & $106.7,170.0$ & $101.3,174.0$ & $97.0,180.0$ \\
\hline \multicolumn{6}{|l|}{ Weight, kg } \\
\hline Mean (SD) & 31 (13) & 29 (11) & 32 (15) & 31 (15) & 30 (14) \\
\hline Median & 26.4 & 25.5 & 25.4 & 23.2 & 24.7 \\
\hline Min, max & $17.1,73$ & $16.3,69.5$ & $15.5,84$ & $14.8,95$ & $14.8,95$ \\
\hline \multicolumn{6}{|c|}{ Body mass index, $\mathrm{kg} / \mathrm{m}^{2}$} \\
\hline Mean (SD) & 17.1 (3.9) & 16.7 (3.0) & $17.7(4.2)$ & $17.2(3.6)$ & 17.2 (3.7) \\
\hline Median & 16.2 & 16.7 & 16.2 & 15.9 & 16.2 \\
\hline Min, $\max$ & $9.8,28.9$ & $9.6,25.5$ & 12.1, 31.2 & $12.7,31.4$ & $9.6,31.4$ \\
\hline
\end{tabular}

The secondary analysis of change in muscle strength from 12 to 52 weeks demonstrated continued improvement in muscle strength in DFZ-treated participants vs worsening in PRED-treated participants (figure 2B). There was a significant improvement in average muscle strength score from week 12 to week 52 in the DFZ $0.9 \mathrm{mg} / \mathrm{kg} / \mathrm{d}$ group compared with the PRED-treated group (LS mean $0.29, p=0.044$, $95 \%$ CI $0.08-0.49$ ). The DFZ $1.2 \mathrm{mg} / \mathrm{kg} / \mathrm{d}$ group had numerical improvement compared to PREDtreated participants from week 12 to week 52 but it did not reach significance (LS mean $0.16, p=0.18$, $95 \% \mathrm{CI}-0.06$ to 0.37 ). From week 12 to week 52 , both DFZ groups demonstrated greater numerical improvements in time from supine to stand, time to climb 4 stairs, and time to run or walk 30 feet compared with the PRED-treated participants, but these did not reach significance. From baseline to week 52, participants in the DFZ $0.9 \mathrm{mg} / \mathrm{kg} / \mathrm{d}$ $(p=0.0461)$ and DFZ $1.2 \mathrm{mg} / \mathrm{kg} / \mathrm{d}(p=0.0012)$ groups had significant improvement in the time to climb 4 stairs compared with PRED. At week 52, the exploratory efficacy endpoint of change in average muscle strength from baseline showed positive results in favor of both doses of DFZ compared with PRED (figure 2C). Mean $\pm S D$ changes in average muscle strength score from baseline at all study visits to week 52 are shown in figure e-1 at Neurology.org.

Physician global assessments did not indicate significant differences among groups at 12 or 52 weeks. Pulmonary function assessments showed a significantly greater benefit with DFZ $1.2 \mathrm{mg} / \mathrm{kg} / \mathrm{d}$ over PRED for the change in FVC from week 12 to week 52. No other differences between treatment groups were observed in assessments of pulmonary function.

Safety evaluations. There were more AEs, serious AEs (SAEs), and AEs leading to discontinuation in PRED-treated participants vs both DFZ groups. The most common AEs observed were those typical of corticosteroids (table 2). The 3 most commonly reported treatment-related events were Cushingoid appearance (136/196 participants; 69.4\%), erythema (82/196 participants; 41.8\%), and hirsutism (77/196 participants, 39.3\%) and were observed in more participants in the prednisone group than in either deflazacort group, and in a greater proportion of participants in the 
Figure 2 Change in average muscle strength score (intention-to-treat population)

Change in average muscle strength score as measured by MRC LS mean $(95 \% \mathrm{Cl})$
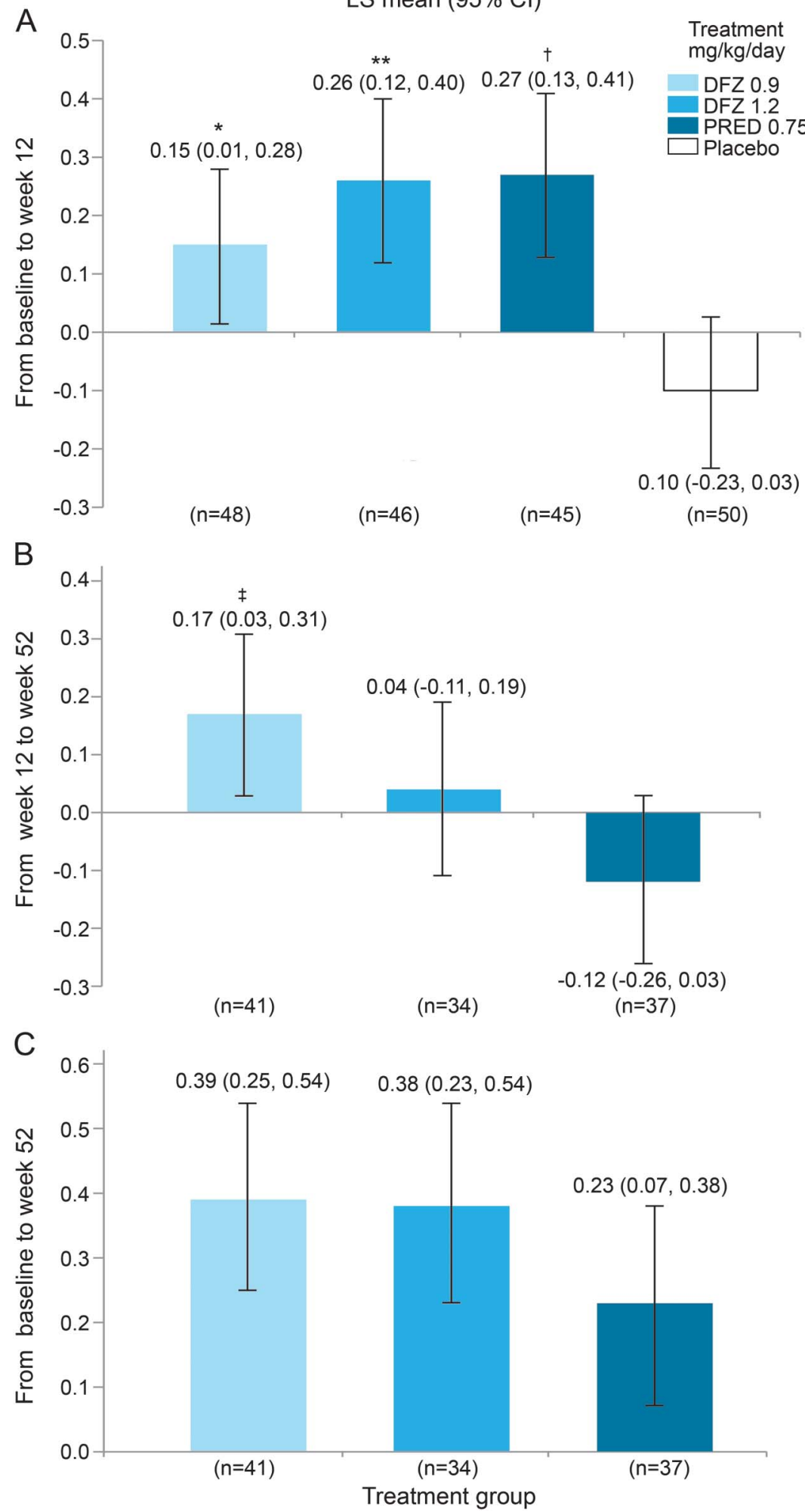

Data are shown as least squares (LS) mean differences (95\% confidence intervals [Cls]) for each of the treatment groups in phase 1 of the study. A positive LS mean value indicates an increase in muscle strength. (A) Change from baseline, which was calculated as a mean of measurements from visit 1 and visit 2 to week 12 (primary endpoint). (B) Change from week 12 to week 52 (secondary endpoint). (C) Change from baseline to week 52. Statistical analysis results are from a mixed-effect repeated measure model with a compound symmetry deflazacort $1.2 \mathrm{mg} / \mathrm{kg} / \mathrm{d}$ group than $0.9 \mathrm{mg} / \mathrm{kg} / \mathrm{d}$ group. Weight gain-related AEs were also more likely to be moderate or severe with PRED compared with DFZ. The higher incidence of weight gain-related AEs is consistent with previously reported data for weight and BMI., ${ }^{5,6,12,13}$ At week 12, there were significant increases in weight (figure 3A) and BMI with PRED vs placebo (weight: LS mean 3.23 vs 1.23, $p=0.0459$, 95\% CI 0.03-3.97; BMI: LS means 1.47 vs $0.16, p=0.0041,95 \%$ CI $0.35-$ 2.29); there were no significant differences between the DFZ groups and placebo. At 52 weeks, the DFZ groups showed significantly smaller increases in weight (figure 3, B and C) and BMI than participants originally randomized to PRED. Mean \pm SD changes in weight and BMI from baseline at all study visits to week 52 are shown in figures e- 2 and e-3, respectively. There was also a nonsignificant result with participants discontinuing treatment due to weight gain-related AEs (e.g., weight increased, central obesity, increased appetite, obesity) on PRED (4.8\%) compared with DFZ (1.5\% for DFZ $0.9 \mathrm{mg} /$ $\mathrm{kg} / \mathrm{d}$ and $3.1 \%$ for $1.2 \mathrm{mg} / \mathrm{kg} / \mathrm{d}$ ).

From baseline to week 12, DFZ $0.9 \mathrm{mg} / \mathrm{kg} / \mathrm{d}$ had a significantly greater decrease in forearm length percentile compared to placebo (LS mean -4.87 vs 1.04, $p=0.0317$ ) and both DFZ dose groups had significantly greater decrease in forearm length percentile than PRED from baseline to 52 weeks (DFZ $0.9 \mathrm{mg} / \mathrm{kg} / \mathrm{d}$ LS mean $-8.05, p=0.0011$; DFZ 1.2 $\mathrm{mg} / \mathrm{kg} / \mathrm{d}$ LS mean $-4.96, p=0.0491 ;$ PRED 0.75 $\mathrm{mg} / \mathrm{kg} / \mathrm{d}$ LS mean 0.85 ) (table e-1). There were no differences in changes in height percentile with the active treatments vs placebo at 12 weeks but DFZ 1.2 $\mathrm{mg} / \mathrm{kg} / \mathrm{d}$ had significantly greater decreases in height percentile from baseline to 52 weeks vs PRED (DFZ $1.2 \mathrm{mg} / \mathrm{kg} / \mathrm{d}$ LS mean $-17.04, p=0.0015$; PRED $0.75 \mathrm{mg} / \mathrm{kg} / \mathrm{d}$ LS mean -7.04 ) (table e- 1 ).

In addition, psychiatric AEs generally appeared at a higher rate in the PRED group vs both DFZ groups. Abnormal behavior, aggression, irritability, and mood swings were more commonly reported in the PRED group. Psychotic disorder was reported more frequently in the low-dose DFZ group. Cataract occurred at a higher rate with daily DFZ $(0.9 \mathrm{mg} / \mathrm{kg}, 4.4 \%$; $1.2 \mathrm{mg} / \mathrm{kg}, 1.5 \%)$ than PRED (1.6\%), consistent with previous literature. ${ }^{14,15}$ Although no cataracts were graded as SAEs, 1 participant in the low-dose DFZ

covariance structure and included treatment group, visit, treatment by visit, stratum, and site as fixed effects, with the baseline value as a continuous covariate. $p$ Values are based on the Dunnett test. $* p=0.0173$ vs placebo; $* * p=$ 0.0003 vs placebo; ${ }^{\dagger} p=0.0002$ vs placebo; ${ }^{\ddagger} p=0.0044$ vs prednisone (PRED) $0.75 \mathrm{mg} / \mathrm{kg} / \mathrm{d}$. DFZ = deflazacort; MRC = Medical Research Council. 


\begin{tabular}{|c|c|c|c|c|c|c|c|c|c|c|}
\hline \multicolumn{11}{|c|}{ nts (TEAEs) ( $\geq 10 \%$ participants in any treatment group) (safety population) } \\
\hline \multirow[b]{2}{*}{ Preferred term } & \multicolumn{2}{|c|}{ Deflazacort, $\mathrm{n}(\%)$} & \multirow[b]{2}{*}{$\begin{array}{l}\text { Prednisone } \\
0.75 \mathrm{mg} / \mathrm{kg} / \mathrm{d} \\
(\mathrm{n}=63)\end{array}$} & \multirow[b]{2}{*}{$\begin{array}{l}\text { Placebo } \\
(n=50)\end{array}$} & \multirow[b]{2}{*}{$\begin{array}{l}\text { Total } \\
(n=196)\end{array}$} & \multirow{2}{*}{$\begin{array}{l}\text { Deflazacort } 0.9 \\
\mathrm{mg} / \mathrm{kg} / \mathrm{d} \text { vs } \\
\text { Placebo, } \\
\mathrm{p} \text { value }\end{array}$} & \multirow{2}{*}{$\begin{array}{l}\text { Deflazacort } 1.2 \\
\mathrm{mg} / \mathrm{kg} / \mathrm{d} \text { vs } \\
\text { Placebo, } \\
\mathrm{p} \text { value }\end{array}$} & \multirow{2}{*}{$\begin{array}{l}\text { Prednisone } 0.75 \\
\mathrm{mg} / \mathrm{kg} / \mathrm{d} \text { vs } \\
\text { placebo, } \\
\mathrm{p} \text { value }\end{array}$} & \multirow{2}{*}{$\begin{array}{l}\text { Deflazacort } 0.9 \\
\mathrm{mg} / \mathrm{kg} / \mathrm{d} \text { vs } \\
\mathrm{prednisone} \\
0.75 \mathrm{mg} / \mathrm{kg} / \mathrm{d} \text {, } \\
\mathrm{p} \text { value }\end{array}$} & \multirow{2}{*}{$\begin{array}{l}\text { Deflazacort } 1.2 \\
\mathrm{mg} / \mathrm{kg} / \mathrm{d} \text { vs } \\
\mathrm{prednisone} \\
0.75 \mathrm{mg} / \mathrm{kg} / \mathrm{d} \text {, } \\
\mathrm{p} \text { value }\end{array}$} \\
\hline & $\begin{array}{l}0.9 \mathrm{mg} / \mathrm{kg} / \mathrm{d} \\
(\mathrm{n}=68)\end{array}$ & $\begin{array}{l}1.2 \mathrm{mg} / \mathrm{kg} / \mathrm{d} \\
(\mathrm{n}=65)\end{array}$ & & & & & & & & \\
\hline Participants with $\geq 1$ TEAE & $58(85.3)$ & 56 (86.2) & $58(92.1)$ & $38(76.0)$ & $174(88.8)$ & 0.2359 & 0.2236 & 0.0318 & 0.2781 & 0.3974 \\
\hline Cushingoid & 41 (60.3) & 45 (69.2) & 49 (77.8) & $6(12.0)$ & $136(69.4)$ & $<0.0001$ & $<0.0001$ & $<0.0001$ & 0.0385 & 0.3198 \\
\hline Erythema & 19 (27.9) & $32(49.2)$ & $33(52.4)$ & $3(6.0)$ & 84 (42.9) & 0.0034 & $<0.0001$ & $<0.0001$ & 0.0071 & 0.7277 \\
\hline Hirsutism & 24 (35.3) & 24 (36.9) & $28(44.4)$ & $1(2.0)$ & 77 (39.3) & $<0.0001$ & $<0.0001$ & $<0.0001$ & 0.3717 & 0.4720 \\
\hline Headache & 15 (22.1) & 22 (33.8) & 22 (34.9) & $11(22.0)$ & 65 (33.2) & 1.0000 & 0.2129 & 0.1500 & 0.1220 & 1.0000 \\
\hline Weight increased & 19 (27.9) & 21 (32.3) & 22 (34.9) & $3(6.0)$ & 62 (31.6) & 0.0034 & 0.0005 & 0.0002 & 0.4524 & 0.8519 \\
\hline Central obesity & $17(25.0)$ & $16(24.6)$ & 27 (42.9) & $2(4.0)$ & 60 (30.6) & 0.0020 & 0.0034 & $<0.0001$ & 0.0415 & 0.0393 \\
\hline Nasopharyngitis & $16(23.5)$ & $15(23.1)$ & $10(15.9)$ & $3(6.0)$ & 43 (21.9) & 0.0114 & 0.0182 & 0.1402 & 0.3809 & 0.3746 \\
\hline Increased appetite & $8(11.8)$ & 8 (12.3) & $12(19.0)$ & $1(2.0)$ & 29 (14.8) & 0.0767 & 0.0753 & 0.0059 & 0.3317 & 0.3369 \\
\hline Abdominal pain upper & $6(8.8)$ & 9 (13.8) & $10(15.9)$ & $4(8.0)$ & 29 (14.8) & 1.0000 & 0.3858 & 0.2582 & 0.2877 & 0.8070 \\
\hline Upper respiratory tract infection & $10(14.7)$ & $6(9.2)$ & $7(11.1)$ & $5(10.0)$ & 27 (13.8) & 0.5794 & 1.0000 & 1.0000 & 0.6093 & 0.7766 \\
\hline Cough & $7(10.3)$ & $8(12.3)$ & $8(12.7)$ & $3(6.0)$ & 26 (13.3) & 0.5147 & 0.3443 & 0.3411 & 0.7858 & 1.0000 \\
\hline Influenza & $4(5.9)$ & $10(15.4)$ & $10(15.9)$ & $2(4.0)$ & 26 (13.3) & 1.0000 & 0.0651 & 0.0631 & 0.0895 & 1.0000 \\
\hline Constipation & $7(10.3)$ & $10(15.4)$ & $4(6.3)$ & $3(6.0)$ & $23(11.7)$ & 0.5147 & 0.1444 & 1.0000 & 0.5343 & 0.1557 \\
\hline Abnormal behavior & $6(8.8)$ & $4(6.2)$ & $9(14.3)$ & $3(6.0)$ & $21(10.7)$ & 0.7315 & 1.0000 & 0.2217 & 0.4138 & 0.1521 \\
\hline Pollakiuria & $10(14.7)$ & $8(12.3)$ & $3(4.8)$ & $1(2.0)$ & 22 (11.2) & 0.0235 & 0.0753 & 0.6284 & 0.0793 & 0.2064 \\
\hline Pyrexia & $6(8.8)$ & $4(6.2)$ & $6(9.5)$ & $4(8.0)$ & 20 (10.2) & 1.0000 & 0.7263 & 1.0000 & 1.0000 & 0.5272 \\
\hline
\end{tabular}


Figure $3 \quad$ Change in weight (intention-to-treat population)

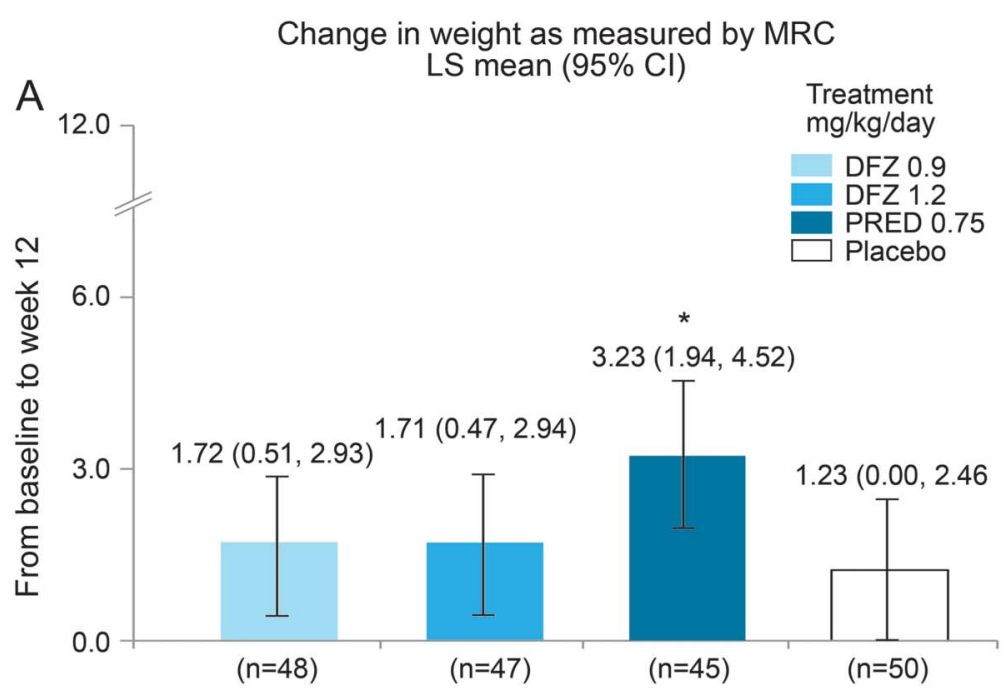

B

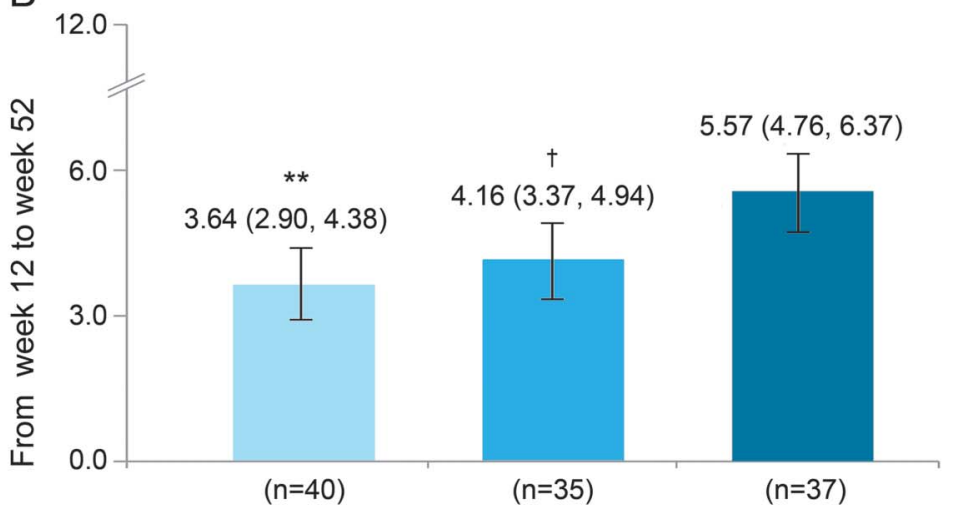

C

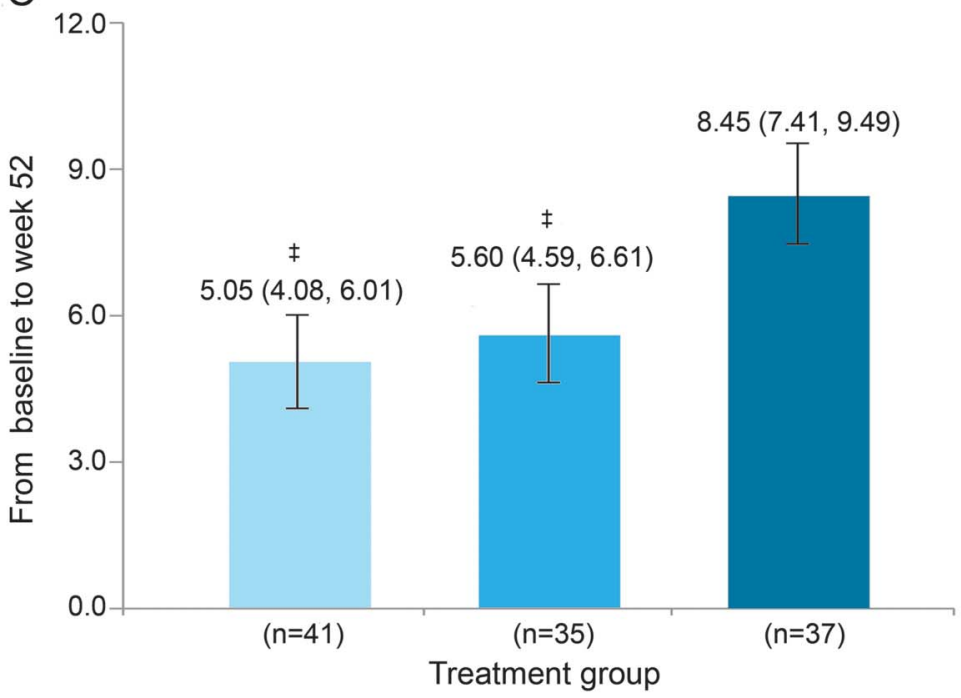

Data are least squares (LS) mean differences (95\% confidence intervals [Cls]) for each of the treatment groups in phase 1 of the study. A positive LS mean value indicates an increase in weight. (A) Change from baseline, which was calculated as a mean of measurements from visit 1 and visit 2 to week 12. (B) Change from week 12 to week 52 . (C) Change from baseline to week 52. Statistical analysis results are from a mixed-effect repeated measure model with a compound symmetry covariance structure and included treatment group, visit, treatment by visit, stratum, and site as fixed effects, with the baseline value as a continuous covariate. $p$ Values are based on the Dunnett test. $* p=0.0459$ vs placebo; $* * p=0.0003$ vs prednisone (PRED) $0.75 \mathrm{mg} / \mathrm{kg} / \mathrm{d} ;{ }^{+} p=0.013$ vs PRED $0.75 \mathrm{mg} / \mathrm{kg} / \mathrm{d}$; ${ }^{\ddagger} p<0.0001$ vs PRED $0.75 \mathrm{mg} / \mathrm{kg} / \mathrm{d}$. DFZ = deflazacort; MRC = Medical Research Council. group discontinued treatment due to cataracts. Other AEs leading to discontinuation in either DFZ group included DMD $(n=1)$, obesity/central obesity $(n=2)$, Cushingoid appearance $(n=1)$, and increased weight $(\mathrm{n}=2)$.

DISCUSSION The efficacy of daily DFZ and PRED for boys with DMD has been demonstrated in randomized controlled trials, showing benefit of both to muscle strength. ${ }^{5,9,12,13,16}$ The $0.9 \mathrm{mg} / \mathrm{kg} / \mathrm{d}$ dose of deflazacort was chosen based on data demonstrating that the potency of prednisone to deflazacort was 1:1.2. ${ }^{17}$ Previous studies had determined PRED 0.75 $\mathrm{mg} / \mathrm{kg} / \mathrm{d}$ to be effective while minimizing side effects over a $1.5 \mathrm{mg} / \mathrm{kg} / \mathrm{d}$ dose. ${ }^{5-7}$ No such study had been completed for DFZ when this study was conducted. Thus 2 dose arms of $0.9 \mathrm{mg} / \mathrm{kg} / \mathrm{d}$ and $1.2 \mathrm{mg} / \mathrm{kg} / \mathrm{d}$ were studied to accomplish the same goal. The current study showed that both DFZ and PRED were superior to placebo over 12 weeks in improving motor strength, consistent with published literature. $^{13,16}$ In addition to preservation of muscle strength, there was improvement in functional measures of time to rise from supine to standing, climbing 4 stairs, and running or walking 30 feet. However, since similar efficacy was seen between the DFZ groups with lower numerical incidence of AEs overall, the $0.9 \mathrm{mg} / \mathrm{kg} / \mathrm{d}$ group was the proposed dose submitted to the Food and Drug Administration.

The AEs observed in the present trial are consistent with known AEs associated with chronic corticosteroid therapy. In general, AEs were higher and more severe with PRED than DFZ, most notably regarding weight gain. The higher incidence of weight gainrelated AEs with PRED vs DFZ was consistent with the weight and BMI data that demonstrated significant weight gain with PRED over placebo at 12 weeks and PRED over DFZ at 52 weeks. Most comparative studies with PRED and DFZ have demonstrated more weight gain with PRED than DFZ; however, not all studies have noted a difference between these treatments in terms of patient weight gain. Over 1 year, PRED-treated participants gained $18 \%$ of their body weight compared with 5\% for DFZ-treated participants. ${ }^{9}$ Similarly, a recent Cooperative International Neuromuscular Research Group publication, which demonstrated the loss of ambulation benefit with DFZ over PRED, found no difference in weight gain between DFZ and PRED but PRED-treated participants were on significantly less of the recommended dose compared to DFZ. ${ }^{18}$

Weight gain is one of the most common AEs associated with corticosteroid use in participants with DMD. Weight gain has implications on the loss of patient ambulation due to increased mechanical load on already impaired muscles. ${ }^{19}$ In the current trial, 
more participants discontinued treatment due to weight gain with PRED than DFZ, a result that is also consistent with earlier data. ${ }^{9}$ This study found that DFZ caused reduced growth compared to prednisone over 52 weeks of treatment. It is possible that the shorter stature with DFZ vs PRED results in a biomechanical advantage that may lead to prolonged ambulation. This finding is consistent with a study that found that the mean age at loss of independent ambulation between boys with short stature (14.8 \pm 2.9 years) and those with normal height $(11.2 \pm 2.4$ years $)$ was significantly different $(p<$ 0.001). ${ }^{20}$ The CINRG study also showed that AEs for growth delay, Cushingoid appearance, and cataracts were higher with DFZ than PRED. ${ }^{18}$ The higher incidence of cataracts with DFZ vs PRED has been reported. $^{21}$

Behavioral abnormalities, such as aggression and irritability, are commonly associated with chronic corticosteroid therapy in patients with DMD and may necessitate a change in treatment. ${ }^{3}$ In the current study, the combined incidence of psychiatric AEs was higher with PRED than DFZ.

A limitation of this study was the 52-week duration of treatment, which does not allow for longterm follow-up to observe the effect of steroids over longer periods of time within this. A longer, prospective randomized study comparing prednisone and deflazacort is currently in progress (FOR DMD). ${ }^{22}$ There are also other intermittent prednisone regimens that may have fewer side effects than daily prednisone dosing. ${ }^{23}$

Overall, this double-blind, randomized, placebocontrolled study demonstrated the effect of DFZ and PRED on muscle strength and motor function in patients with DMD. Over 1 year of treatment, DFZ was better tolerated and resulted in a lower incidence of weight gain and psychiatric AEs, which are the most common reasons for discontinuing treatment. ${ }^{24}$ Data from this study should be taken into account when deciding which GC to start in a boy with DMD.

\section{AUTHOR CONTRIBUTIONS}

Robert C. Griggs: drafting/revising the manuscript, study concept or design, analysis or interpretation of data, accepts responsibility for conduct of research and final approval, acquisition of data, obtaining funding. J. Phillip Miller: study concept or design, analysis or interpretation of data, accepts responsibility for conduct of research and final approval, statistical analysis. Cheryl R. Greenberg: drafting/revising the manuscript, analysis or interpretation of data, accepts responsibility for conduct of research and final approval, study supervision. Darcy L. Fehlings: drafting/revising the manuscript, analysis or interpretation of data, accepts responsibility for conduct of research and final approval, acquisition of data, study supervision. Alan Pestronk: drafting/revising the manuscript, study concept or design, analysis or interpretation of data, accepts responsibility for conduct of research and final approval. Jerry R. Mendell: drafting/revising the manuscript, study concept or design, accepts responsibility for conduct of research and final approval, study supervision, obtaining funding. Richard T. Moxley, III: drafting/ revising the manuscript, study concept or design, analysis or interpretation of data, accepts responsibility for conduct of research and final approval, acquisition of data, study supervision. Wendy M. King: drafting/revising the manuscript, study concept or design, analysis or interpretation of data, accepts responsibility for conduct of research and final approval, acquisition of data. John T. Kissel: drafting/revising the manuscript, study concept or design, accepts responsibility for conduct of research and final approval, contribution of vital reagents/tools/ patients, acquisition of data, study supervision. Valerie A. Cwik: drafting/revising the manuscript, accepts responsibility for conduct of research and final approval, acquisition of data, study supervision. Michel Vanasse: drafting/revising the manuscript, study concept or design, accepts responsibility for conduct of research and final approval, study supervision. Julaine M. Florence: drafting/revising the manuscript, study concept or design, accepts responsibility for conduct of research and final approval, acquisition of data, study supervision. Shree Pandya: drafting/revising the manuscript, accepts responsibility for conduct of research and final approval, acquisition of data, study supervision. Jordan S. Dubow: drafting/revising the manuscript, analysis or interpretation of data, accepts responsibility for conduct of research and final approval. James M. Meyer: drafting/revising the manuscript, accepts responsibility for conduct of research and final approval, acquisition of data.

\section{ACKNOWLEDGMENT}

The authors thank Jonathan Sokolowski, PhD, of ACCESS Medical, LLC, for editorial assistance including production of tables and figures. ACCESS Medical, LLC, received funding from Marathon Pharmaceuticals, LLC, for editorial assistance. The authors also thank Drs. Michael Brooke, Gerald Fenichel, J.P. Bouchard, and J. Robison for their contributions to the performance of the study.

\section{STUDY FUNDING}

This study was sponsored with funding provided by Nordic Merrill Dow and the Muscular Dystrophy Association (MDA).

\section{DISCLOSURE}

R. Griggs is a consultant for Sarepta Therapeutics, Bamboo Therapeutics, Marathon Pharmaceuticals, LLC, and PTC Therapeutics, and holds NIH, MDA, and PPMD support for studies on corticosteroids in DMD. J. Miller, C. Greenberg, D. Fehlings, and A. Pestronk report no disclosures relevant to the manuscript. J. Mendell has served as a principal investigator on studies supported by Sarepta Therapeutics and aveXis Inc. R. Moxley, W. King, and J. Kissel report no disclosures relevant to the manuscript. V. Cwik is an employee of the MDA. M. Vanasse, J. Florence, and S. Pandya report no disclosures relevant to the manuscript. J. Dubow is an employee of Marathon Pharmaceuticals, LLC, and holds stock options. J. Meyer is an employee of Marathon Pharmaceuticals, LLC, and holds stock options. Robert C. Griggs takes full responsibility for the data, the analyses and interpretation, and the conduct of the research. Dr. Griggs has full access to all of the data and has the right to publish any and all data separate and apart from any sponsor. The protocol (and any amendments) and the statement of informed consent were approved by an institutional review board (IRB) prior to each center's initiation. Marathon Pharmaceuticals, LLC, is issuing this clinical study report after Nordic Merrell Dow Research Inc. discontinued development of deflazacort in the United States for the treatment of patients with DMD. A confirmed list of IRBs involved is not available. Available information on IRBs consulted, based on participating physician recall, is available at the request of the editor. Go to Neurology.org for full disclosures.

Received March 10, 2016. Accepted in final form July 29, 2016.

\section{REFERENCES}

1. Mendell JR, Shilling C, Leslie ND, et al. Evidence-based path to newborn screening for Duchenne muscular dystrophy. Ann Neurol 2012;71:304-313. 
2. Moxley RT III, Ashwal S, Pandya S, et al. Practice parameter: corticosteroid treatment of Duchenne dystrophy: report of the Quality Standards Subcommittee of the American Academy of Neurology and the Practice Committee of the Child Neurology Society. Neurology 2005;64:13-20.

3. Bushby K, Finkel R, Birnkrant DJ, et al. Diagnosis and management of Duchenne muscular dystrophy, part 1: diagnosis, and pharmacological and psychosocial management. Lancet Neurol 2010;9:77-93.

4. Bushby K, Finkel R, Birnkrant DJ, et al. Diagnosis and management of Duchenne muscular dystrophy, part 2: implementation of multidisciplinary care. Lancet Neurol 2010;9:177-189.

5. Griggs RC, Moxley RT III, Mendell JR, et al. Prednisone in Duchenne dystrophy: a randomized, controlled trial defining the time course and dose response: clinical Investigation of Duchenne Dystrophy Group. Arch Neurol 1991;48:383-388.

6. Fenichel GM, Mendell JR, Moxley RT, et al. A comparison of daily and alternate-day prednisone therapy in the treatment of Duchenne muscular dystrophy. Arch Neurol 1991;48:575-579.

7. Griggs RC, Moxley RT, Mendell JR, et al. Duchenne dystrophy: randomized controlled trial of prednisone (18 months) and azathioprine (12 months). Neurology 1993; 43:520-527.

8. Nathanson G, Winters G, Testa E. Steroids possessing nitrogen atoms: 3 : synthesis of new highly active corticoids [17-alpha, 16-alpha-d]oxazolino steroids. J Med Chem 1967;10:799-802.

9. Bonifati MD, Ruzza G, Bonometto P, et al. A multicenter, double-blind, randomized trial of deflazacort versus prednisone in Duchenne muscular dystrophy. Muscle Nerve 2000;23:1344-1347.

10. Reitter B. Deflazacort vs. prednisone in Duchenne muscular dystrophy: trends of an ongoing study. Brain Dev 1995(17 Suppl):39-43.

11. Brooke MH. A randomized trial of deflazacort and prednisone in Duchenne muscular dystrophy: efficacy and toxicity. Neurology 1996;46:A476.

12. Mendell JR, Moxley RT, Griggs RC, et al. Randomized, double-blind six-month trial of prednisone in Duchenne's muscular dystrophy. N Engl J Med 1989;320:1592-1597.
13. Mesa LE, Dubrovsky AL, Corderi J, Marco P, Flores D. Steroids in Duchenne muscular dystrophy-deflazacort trial. Neuromuscul Disord 1991;1:261-266.

14. Biggar WD, Harris VA, Eliasoph L, Alman B. Long-term benefits of deflazacort treatment for boys with Duchenne muscular dystrophy in their second decade. Neuromuscul Disord 2006;16:249-255.

15. Houde S, Filiatrault M, Fournier A, et al. Deflazacort use in Duchenne muscular dystrophy: an 8-year follow-up. Pediatr Neurol 2008;38:200-206.

16. Angelini C, Pegoraro E, Turella E, Intino MT, Pini A, Costa C. Deflazacort in Duchenne dystrophy: study of long-term effect. Muscle Nerve 1994;17:386-391.

17. Lund B, Egmose C, Jorgensen S, Krogsgaard MR. Establishment of the relative antiiflammatory potency of deflazacort and prednisone in polymyalgia rheumatica. Calcif Tissue Int 1987;41:316-320.

18. Bello L, Gordish-Dressman H, Morgenroth LP, et al. Prednisone/prednisolone and deflazacort regimens in the CINRG Duchenne natural history study. Neurology 2015; 85:1048-1055.

19. Bianchi ML, Mazzanti A, Galbiati E, et al. Bone mineral density and bone metabolism in Duchenne muscular dystrophy. Osteoporos Int 2003;14:761-767.

20. Mah JK, Hu F, McDonald CM. Short stature prolonged ambulation in boys with Duchenne muscular dystrophy. Can J Neurol Sci 2012;39:S13.

21. Schara U, Mortier W. Long-term steroid therapy in Duchenne muscular dystrophy: positive results versus side effects. J Clin Neuromuscul Dis 2001;2:179-183.

22. Griggs RC, Bushby K. Finding the optimum regimen for Duchenne muscular dystrophy (FOR-DMD). In: ClinicalTrials.gov. Bethesda, MD: National Library of Medicine; 2000. Available at: https://clinicaltrials.gov/ct2/show/ NCT01603407?term =for-dmd\&rank=1: NCT01603407. Accessed January 26, 2016.

23. Escolar DM, Hache LP, Clemens PR, et al. Randomized trial of weekend vs daily prednisone in Duchenne muscular dystrophy. Neurology 2011;77:444-452.

24. Matthews DJ, James KA, Miller LA, et al. MDSTARnet: use of corticosteroids in a population-based cohort of boys with Duchenne and Becker muscular dystrophy. J Child Neurol 2010;25:1319-1324.

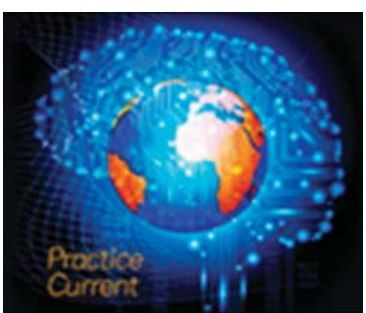

\section{Practice Current: An interactive exchange on controversial topics}

"When do you stop antiepileptic drugs in patients with genetic generalized epilepsies and in patients with focal epilepsies?"

Share your own best practices. Take the survey now!

Neurology ${ }^{\circledR}$ Clinical Practice http://tinyurl.com/NCPPC 


\section{Neurology}

Efficacy and safety of deflazacort vs prednisone and placebo for Duchenne muscular dystrophy

Robert C. Griggs, J. Phillip Miller, Cheryl R. Greenberg, et al.

Neurology 2016;87;2123-2131 Published Online before print August 26, 2016

DOI 10.1212/WNL.0000000000003217

This information is current as of August 26, 2016

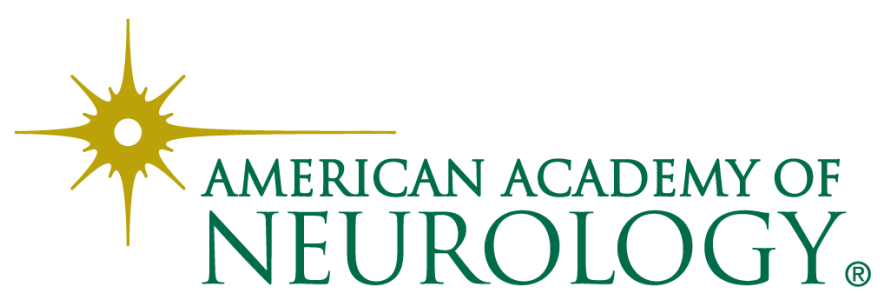




\section{Updated Information \& Services}

\section{Supplementary Material}

\section{References}

Citations

Subspecialty Collections

\section{Permissions \& Licensing}

\section{Reprints}

including high resolution figures, can be found at: http://n.neurology.org/content/87/20/2123.full

Supplementary material can be found at: http://n.neurology.org/content/suppl/2016/08/26/WNL.0000000000003 217.DC1 http://n.neurology.org/content/suppl/2016/11/14/WNL.0000000000003 217.DC2

This article cites 22 articles, 4 of which you can access for free at: http://n.neurology.org/content/87/20/2123.full\#ref-list-1

This article has been cited by 7 HighWire-hosted articles: http://n.neurology.org/content/87/20/2123.full\#\#otherarticles

This article, along with others on similar topics, appears in the following collection(s):

\section{All Clinical trials}

http://n.neurology.org/cgi/collection/all_clinical_trials

All Neuromuscular Disease

http://n.neurology.org/cgi/collection/all_neuromuscular_disease

All Pediatric

http://n.neurology.org/cgi/collection/all_pediatric

Class I

http://n.neurology.org/cgi/collection/class_1

Muscle disease

http://n.neurology.org/cgi/collection/muscle_disease

Information about reproducing this article in parts (figures,tables) or in its entirety can be found online at:

http://www.neurology.org/about/about_the_journal\#permissions

Information about ordering reprints can be found online:

http://n.neurology.org/subscribers/advertise rights reserved. Print ISSN: 0028-3878. Online ISSN: 1526-632X.

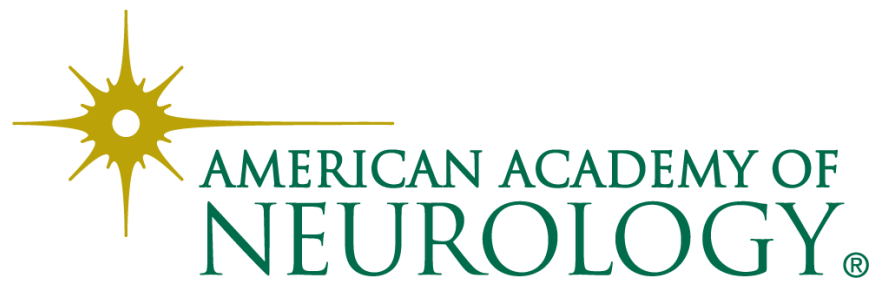

